\title{
Analysis of Re Influence on MILD Combustion of Gas Turbine
}

\author{
Lijun Wang ${ }^{1}$, Dongdong $\mathbf{Q i}^{2}$, Xiaowei Sui ${ }^{2}$, Xin Xie ${ }^{1}$ \\ ${ }^{1}$ Shenyang Aerospace University, Shenyang, College of Energy and Environment \\ ${ }^{2}$ Shenyang Aerospace University, Division of Aerospace Engineering, Shenyang
}

Received January, 2013

\begin{abstract}
The paper numerical studied the MILD(Moderate or Intense Low-oxygen Dilution) combustion mode and performances in the designed gas turbine chamber. The influence of air jet Re number on flue gas recycles ratio Kv and hereby on kerosene fuel MILD combustion were modeled. For fixed equivalence ratio, increasing the air jet Re number to the Kv value of 3.3 - 3.8, MILD combustion mode will be formed. It has MILD combustion performances of volume combustion, excellent outlet temperature field and very low pollutant emissions. Combustor confinement has little effects on MILD combustion. Calculating results agree with other's similar experimental data.
\end{abstract}

Keywords: Gas Turbine; MILD Combustion; Combustion Performance; Numerical Study

\section{Introduction}

In the last decades of the 20th century, there are many researches focus on the high efficiency and low emission combustion. New types of combustion mode and theory such as LPP(Lean Premix Pre-vaporized Combustion) and RQL(Rich Burn-Quench-Lean Burn) had put forward. However, these combustion molds can hardly satisfy the requirements of high efficiency and low emissions simultaneously unless combined with the staged combustion or variable geometry combustor, and has not been applied to gas turbine successfully[1]. The current MILD (Moderate \& Intense Low Oxygen Dilution) mode have more advantageous performances of high combustion efficiency and super low emissions[2].

MILD combustion is a burning mode under the condition of low oxygen diluted, which is also known as Flameless Combustion, Colourless Combustion or FLOX (Flameless Oxidation). MILD combustion mode has the characteristics of volume or dispersion combustion which eliminates the flame frontal surface under normal temperature air. Gas, liquid, solid and other low caloric fuel can be extensively used to reduce pollutants emission and combustion noise[2]. From 1991 when Wunning[3] applied flameless combustion to industrial furnace by high speed jet entrain flue gas on, it is necessary to preheat the air above 1000K for MILD combustion mode at the beginning. For the current period, all kinds of fuel can be used for MILD combustion based

"Sponsored by The Aero Science Foundation of China (NO. 20112B 54005) on the air jet of normal temperature[4-6]. The application scope of MILD combustion is expanded from various industrial furnaces to high-tech field includes gas turbine and aeroengine[7-11]. Great differences of operating condition between industrial furnace and gas turbine lead to grand technical challenge [10]. Nowadays, this research is on a stage of rapid development including mechanism analysis, experiment and numerical simulation.

\section{Model and Computational Grid}

Figure 1 shows the 1/12 symmetrical body of the chamber and the local computational mesh of crosssection near the head of chamber. Tubular combutor model combustor is adopped and the working pressure in chamber is $0.4 \mathrm{MPa}$ with the combustion intensity of 25 $\mathrm{MW} /(\mathrm{m} 3 \cdot \mathrm{atm})$. The model chamber is composed of head section and flame tube. The air into the flame tube injected cooling air in the casing, which improve the air flow distribution. 12 air-atomizer noozles and 12 dilution holes are installed circumferential distributed evenly. The

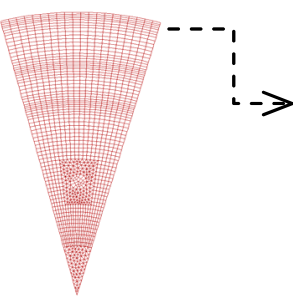

(a) Local grid dissection

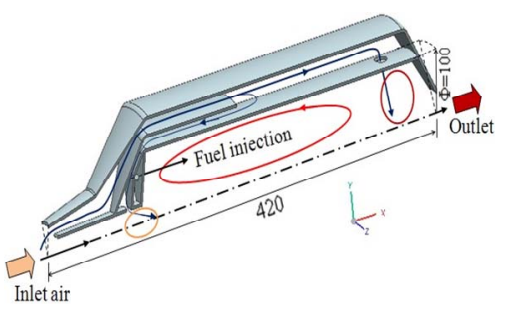

(b) $1 / 12$ symmetric body
Figure 1. 1/12 Model chamber and local section mesh. 
chamber dimension is $100 \mathrm{~mm} \times 420 \mathrm{~mm}$ with two outlet styles of shrinkage tube and direct tube(labeled by dotted line).

The model chamber is divided by structured and unstructured mixing meshes for its complicated structures. Grid numbers of direct tube and shrinking outlet are $884,869-857,855$ respectively.

\section{Mathematical Models}

\subsection{The Governing Equations}

The basic governing equations for continuous phase of turbulent combustion reaction flow are expressed as

$$
\frac{\partial}{\partial x_{j}}\left(\rho \bar{u}_{i} \phi\right)=\frac{\partial}{\partial x_{j}}\left(\Gamma_{\phi} \frac{\partial \phi}{\partial x_{j}}\right)+S_{\phi}+S_{p, \phi}
$$

in which $\overline{u_{i}}$ is the time average value of velocity component, $\Phi$ is the universal variant of turbulent velocity component, turbulent kinetic energy $\mathrm{k}$ and its dissipation rate $\varepsilon$, total enthalpy $\mathrm{h}$ and mass fraction $\mathrm{m}_{\mathrm{i}}$ ( $\mathrm{i}=\mathrm{C}_{12} \mathrm{H}_{23}, \mathrm{O}_{2}, \mathrm{CO}_{2}, \mathrm{H}_{2} \mathrm{O}, \mathrm{N}_{2}, \mathrm{CO}, \mathrm{H}_{2}, \mathrm{NO}$ ). $\Gamma_{\phi}$ is effective diffusion coefficient, $S_{\phi}$ is the source term of the gas continuous phase, $S_{p, \phi}$ is the interaction source term between the particles phase of kerosene and continuous phase, $\rho$ stands for density of gas phase, which depends on the gas state equation. The governing equations are closed by Realizable k- $\varepsilon$ turbulence model and standard wall function is adopted near the wall. $\mathrm{C}_{12} \mathrm{H}_{23}$ represents aviation kerosene. A joint model with multistage finite-rate chemical reaction and EDC model is adopted to simulate the interaction between the turbulence and chemical reaction, revealed in formula(2). The reaction rate is controlled by the minor rate of EDC conceptual model (3) and finite-rate chemical reaction model rate (4)

$$
\begin{aligned}
& R_{i}=-\min \left(R_{\text {eddy }}, R_{\text {Chem }}\right) \\
& R_{\text {eddy }}=4.0 \frac{\varepsilon}{k} \min \left(\frac{m_{o x}}{r_{f u}}, m_{f u}\right) \\
& R_{\text {Chem }}=A[\text { fuel }]^{a}[\text { oxygen }]^{b} \exp (-E / R T)
\end{aligned}
$$

$r_{f u}$ is chemical equivalence ratio. $\mathrm{A}, \mathrm{E}$ and $\mathrm{T}$ stand for pre-exponential factor, activation energy and gas temperature respectively. Thermal $\mathrm{NO}$ and fast $\mathrm{NO}$ model are both used for NOx generation. $\mathrm{P}_{1}$ Radiation model and radiative properties calculation of flue gas are used. Discrete phase of oil fuel particles are calculated by discrete random wander model, and the Lagrange equation describing fuel particles speed, mass and rate of temperature change is solved. The source term $S_{p, \phi}$ in equation (1) is calculated by PSI-CELL model. The size of atomized particles conforms Rosin-Rammler distribu- tion, and the effect of gas turbulent fluctuation on particles speed is considered. Temperature polynomial function is used for describing physicochemical properties of gas component and fuel. Thermal-gas-solid coupled boundary condition is advisable. CFD calculation is carried on the commercial software FLUENT6.3 designed by ANSYS[12].

\subsection{Calculation Conditions}

Air inlet temperature from the compressor of gas turbine is assumed $800 \mathrm{~K}$ and equivalence ratio $\Phi$ is 0.62 . Effect of outlet on MILD combustion defined by geometric factor $\mathrm{g}=$ doutlet/dtube is 0.44 and 1 for shrinkage and direct outlets respectively. The calculation conditions are listed in Table 1.

\section{Results and Discussion}

\subsection{Effect of Rein on MILD Combustion}

1) MILD Combustion Temperature Field

Figure 2 shows that, when Rein is larger than $1.13 \times$ 105, MILD combustion mode has formed volume flame of flame front surface disappears, local temperature difference is less than $50 \mathrm{~K}$ after flame lift off zone, $\mathrm{T}_{\text {aver }}$ is about $1540 \sim 1541 \mathrm{~K}$.

Table 1. Calculation conditions.

\begin{tabular}{cccc}
\hline $\mathbf{R e}_{\text {in }}$ & Fuel mass flow $(\mathbf{k g} / \mathbf{s})$ & $\boldsymbol{\Phi}$ & $\boldsymbol{g}$ \\
\hline $1.13 \times 10^{5}$ & 0.00144 & 0.62 & $1 / 0.44$ \\
$1.50 \times 10^{5}$ & 0.00192 & 0.62 & $1 / 0.44$ \\
$1.88 \times 10^{5}$ & 0.00240 & 0.62 & $1 / 0.44$ \\
\hline
\end{tabular}

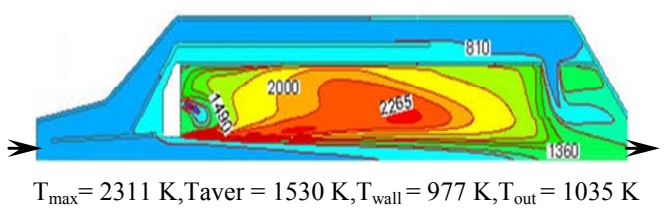

(a) $\mathrm{Re}_{\text {in }}=1.13 \times 10^{5}$

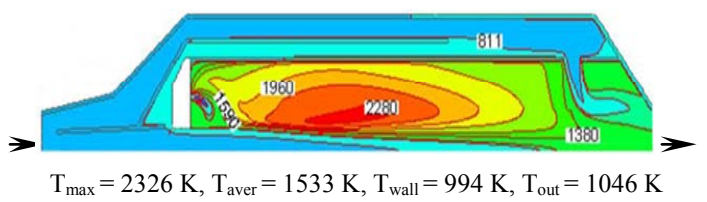

(b) $\mathrm{Re}_{\text {in }}=1.50 \times 10^{5}$

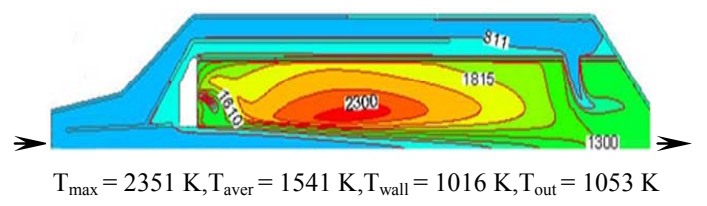

(c) $\mathrm{Re}_{\text {in }}=1.88 \times 10^{5}$

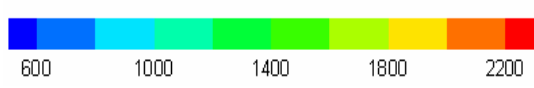

Figure 2. Effect of Rein on temperature field. 
2) Flue Gas Recirculation Rate $K_{v}$

Previous MILD combustion results of experiment and calculation indicated flue gas recirculation rate $\mathrm{K}_{\mathrm{v}}$ was important for MILD combustion mode[2]. The larger the combustion air jet momentum is, the greater of flue gas recirculation rate $\mathrm{K}_{\mathrm{v}}$, and the lower oxygen concentration[11]. High velocity air jet which induced stiring action of momentum, that accelerated by combustion heat release and viscous shearing force is main influence factor of $\mathrm{K}_{\mathrm{v}}$. Numerical simulation is an effective means of researching on this complicated action. Local $\mathrm{K}_{\mathrm{v}}(\mathrm{x})$ value is defined as

$$
\begin{aligned}
K_{v}(x) & =\frac{M_{\text {rec }}(x)}{M_{\text {air }}+M_{\text {injection }}+M_{\text {fuel }}} \\
& =\frac{\iint_{A(x)} \rho_{\text {rec }} v_{\text {rec }} d A(x)}{M_{\text {air }}+M_{\text {injection }}+M_{\text {fuel }}}
\end{aligned}
$$

$M_{\text {rec }}$ is the mass flow of flue gas, $\mathrm{kg} / \mathrm{s} . \mathrm{M}_{\text {air }}$ and $\mathrm{M}_{\text {fuel }}$ are mass flow rate of air jet and kerosene, $\mathrm{kg} / \mathrm{s}$. $\mathrm{M}_{\text {injection }}$ is the secondary mass flow rate of injected air from the casing. $\mathrm{A}(\mathrm{x})$ is local across section area of flame tube, $\mathrm{m}^{2}$. $\rho_{\text {rec }}, v_{\text {rec }}$ is local density and velocity separately.

For ordinary combustion mode like bluff body burning, $\mathrm{K}_{\mathrm{v}}$ is kept $0.3-0.5$, but $\mathrm{Kv}$ for MILD combustion is larger than 3[2]. The calculating results of $\mathrm{Kv}$ in the gas turbine this MILD chamber for kerosene fuel is showed in Figure 4, which can be verified by Craya-Curtet experimental formula[13].

$$
K_{v}(x)=0.32 \sqrt{\frac{\rho_{\text {flue }}}{\rho_{\text {in }}}} \cdot \frac{x-x_{0}}{D_{\text {in }}}+1
$$

$D_{\text {in }}$ is the inner diameter of the injector, m. $\rho$ flue is flue gas density in the reference temperature, $\mathrm{kg} / \mathrm{m}^{3}$. $\rho$ in is the reactant density of inlet temperature, $\mathrm{kg} / \mathrm{m}^{3} \cdot \mathrm{x}_{0}$ is the original injecting coordinate, $\mathrm{m}$.

Levy Y. etc. had researched on the MILD combustion mode in the gas turbine chamber and indicate that MILD combustion mode may be built as $\mathrm{Kv}$ is larger than $3.0[10]$. Figure 3 showed that when Rein $\geqslant 1.13 \times 105$, at the flame lift-off location $\mathrm{x}=0.132 \mathrm{~m}$, its local $\mathrm{Kv}$ is $1.365,1.191$ and 1.182 respectively, are both larger than $0.3 \sim 0.5$ of ordinary stable combustion mode such as bluff body combustion. The backflow entrainment of high temperature flue gas has effects of heating and ignition on lift off zone of combustible mixture and may induce MILD combustion mode. Furthermore, $\mathrm{Kv}$ at recirculation zone center is between 3.3 and 3.8 in the Figure 3, which represents the formed MILD mode and corresponds to the existing experiment results of fuels. The entrainment air from casing has a stabilized effect on the $\mathrm{Kv}$, which is beneficial to MILD state. $K_{v}$ calculation results fit the Craya-Curtet formula in Figure 3.
3) NOx Emossion

MILD combustion performance of pollutant of $\mathrm{NOx}$ emisssion show in Figure 4.

When Rein $\geqslant 1.13 \times 105$ i.e. $\mathrm{Kv}$ is larger than 3.3 , the average combustion temperature is about 1530 1541 $\mathrm{K}$ and NOx emission is between 15 and $16.5 \mathrm{ppm}$ analogous to $18 \mathrm{ppm}$ of experiment result[14].

4) Outlet temperature field quality

The temperature distribution coefficient can be described as OTDFmax, which is showed as

$$
\mathrm{OTDF}_{\text {max }}=\frac{T_{4 \max }-\bar{T}_{t 4}}{\bar{T}_{t 4}-\bar{T}_{3}}
$$

$\mathrm{T}_{4 \max }$ is outlet temperature peak value, $\mathrm{T}_{4}$ is the outlet circumferential average temperature, $T_{3}$ is the entrance average temperature. $\mathrm{OTDF}_{\max }$ calculation results are between 0.293 and 0.267 , decrease with Rein increasing, but far less than 0.35 of ordinary combustor. The lager Rein, the smaller OTDFmax. Temperature field quality of outlet section is clearly uniform.

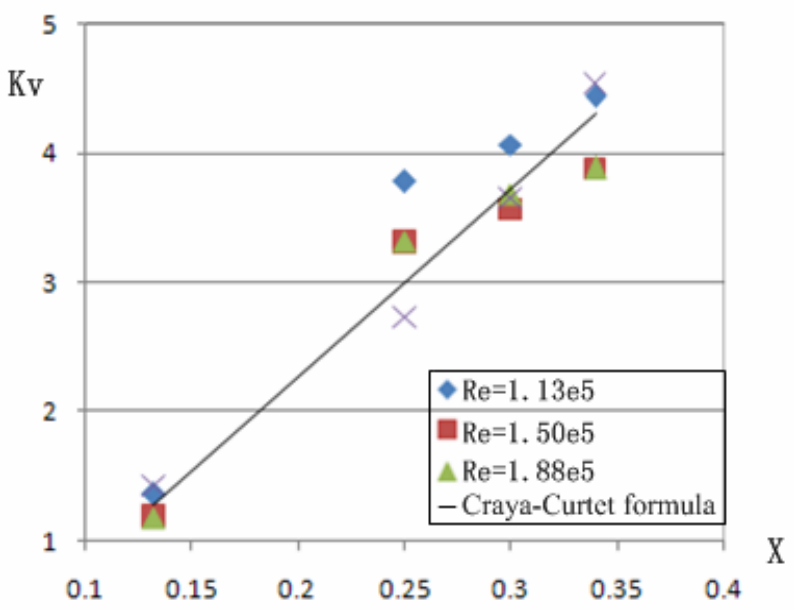

Figure 3. $\mathrm{Kv}(\mathrm{x})$ calculating vs. experimental.

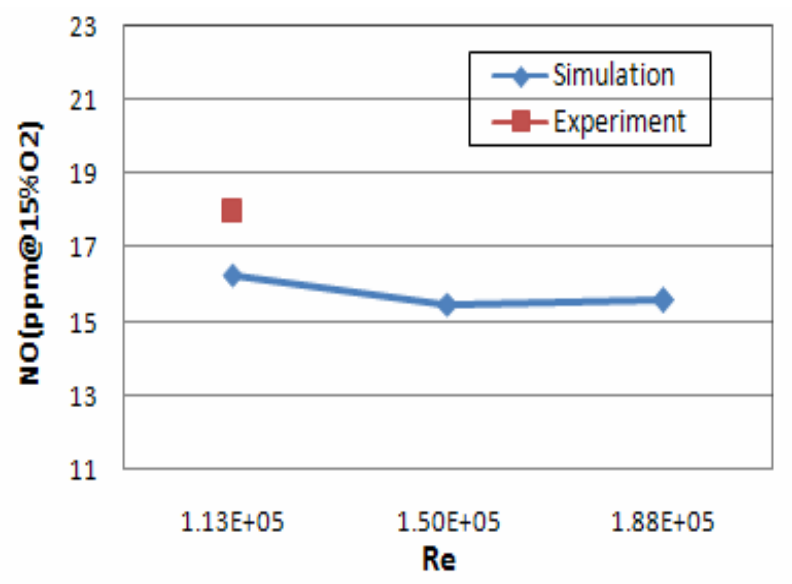

Figure 4. NOx Emission(ppm@15\% $\left.\mathrm{O}_{2}\right)$. 
Table 2. Impact of confinement on MILD combustion.

\begin{tabular}{ccccccc}
\hline $\mathbf{R e}_{\text {in }}$ & \multicolumn{2}{c}{$\mathbf{1 . 1 3} \times \mathbf{1 0}^{\mathbf{5}}$} & \multicolumn{2}{c}{$\mathbf{1 . 5 0} \times \mathbf{1 0}^{\mathbf{5}}$} & \multicolumn{2}{c}{$\mathbf{1 . 8 8}^{2} \times \mathbf{1 0}^{\mathbf{5}}$} \\
\hline Factor $\mathbf{g}$ & 1 & 0.44 & 1 & 0.44 & 1 & 0.44 \\
$\mathrm{KV}$ & 3.52 & 3.78 & 3.50 & 3.31 & 3.51 & 3.32 \\
$\mathrm{~T}_{\text {aver }}(\mathrm{K})$ & 1469 & 1530 & 1464 & 1533 & 1541 & 1469 \\
$\mathrm{OTDF}_{\max }$ & 0.16 & 0.29 & 0.16 & 0.27 & 0.16 & 0.27 \\
$\mathrm{NO}_{\mathrm{x}}$ & 14.1 & 16.3 & 13.3 & 15.5 & 12.3 & 15.6 \\
$\varepsilon(\%)$ & 98.3 & 99.5 & 99.4 & 99.4 & 99.4 & 99.4 \\
\hline
\end{tabular}

Table 3. Calculation vs. similar experiments.

\begin{tabular}{lcc}
\hline \multicolumn{1}{c}{ Similar items } & calculation & experiment \\
\hline Fuel & Kerosene & Liquid propane \\
$\mathrm{T}_{\text {air }}(\mathrm{K})$ & 800 & 798 \\
$\Phi$ & 0.62 & 0.62 \\
$\mathrm{Kv}$ & 3.5 & 3.5 \\
$\mathrm{Tmax}(\mathrm{K})$ & $2323 \sim 2332$ & $\approx 1873$ \\
$\mathrm{NO}_{\mathrm{x}}\left(\mathrm{ppm} @ 15 \% \mathrm{O}_{2}\right)$ & $12.3 \sim 14.1$ & $\approx 18$ \\
$\mathrm{CO}\left(\mathrm{ppm} @ 15 \% \mathrm{O}_{2}\right)$ & $8.1 \sim 37.8$ & $\approx 20$ \\
\hline
\end{tabular}

\subsection{Effect of Geometric Constraint}

The calculating result of changing chamber constraint condition is stated in Table 2.

The combustion efficiency $\varepsilon$ in Table $\mathbf{2}$ is defined as

$$
\varepsilon=\left[1-E I_{C O} \times\left(\frac{\Delta H_{C O}}{\Delta H_{C_{12} H_{23}}}\right)-E I_{H C}\right] \times 100 \%
$$

$\mathrm{EI}_{\mathrm{CO}}$ and $\mathrm{EI}_{\mathrm{HC}}$ are emission index of $\mathrm{CO}$ and $\mathrm{HC}, \mathrm{g} / \mathrm{kg}$. $\triangle \mathrm{H}_{\mathrm{CO}}$ and $\triangle \mathrm{H}_{\mathrm{C} 12 \mathrm{H} 23}$ is the low heating value of $\mathrm{CO}$ and $\mathrm{C}_{12} \mathrm{H}_{23}$. In the Table 2, MILD combustion mode and performance influenced by Re number conform to the gas turbine flameless combustrion experiment results [14].

\subsection{Simulation Comparison with Test}

Table 3 contains the numerical results comparison with the experimental of similar conditions[14]. The calculation results are coincidence with experiment.

\section{Conclusions}

For the designed MILD model chamber, effect of Reynolds number on MILD combustion has been numerical simulated, which is concluded as follows:

1) Air jet Reynolds number has important effect on the high temperature flue gas recycling rate $\mathrm{K}_{\mathrm{v}}$ and MILD combustion mode. MILD combustion mode is formed when $\mathrm{K}_{\mathrm{v}}$ larger than $3.3 \sim 3.8$.

2) The formed MILD combustion has characteristics of space reaction, high combustion efficient, very lower NOx and $\mathrm{CO}$ emissions, and good equality temperature field of outlet section.

3) MILD chamber constraint condition has little effect on MILD combustion mode.

The calculation results are conformed to the associated experiments and laws, which have engineering reference value for MILD applications to gas turbine.

\section{REFERENCES}

[1] Z. Nikolao, "Low-NOx Combustor Development Pursued within the Scope of the Engine 3E German National Research Program in a Cooperative Effort among Engine Manufacturer, University of Karlsruhe and DLR German Aerospace Research Center," Aerospace Science and Technology, Vol. 6, No. 7, 2002, pp. 531-544. doi.org/10.1016/S1270-9638(02)01179-3

[2] P F Li, J C Mi, B. B. Dally, et al., "Progress and Recent Trend in MILD Combustion," China Science and Technology, Vol. 54, 2011, pp. 255-269. doi:10.1007/s11431-010-4257-0

[3] J. A Wunning and J. G. Wunning, "Flameless Oxidation to Reduce Thermal NO Formation," Progress in Energy Combustion Science, Vol. 23, No. 1, 1997, pp. 81-94.

[4] A. K. Gupta Proceedings of 2nd International Seminar on High Temperature Combustion in Industrial FurnaceJemkontoret-KTH, Stockholm, Sweden, January, 2000, pp. 17-18

[5] F. Michael, "New Combustion Systems for Gas Turbines(NGT)," Applied Thermal Engineering, Vol. 24, No. 11-12, 2004, pp. 1551-1559.

doi:10.1016/j.applthermaleng.2003.10.024

[6] K. Vaibhav Arghode and K. Ashwani Gupta, "Investigation of Forward Flow Distributed Combustion for Gas Turbine Application," Applied Energy, Vol. 88, 2011, pp. 29-40. doi:10.1016/j.apenergy.2010.04.030

[7] K. Vaibhav Arghode and K. Ashwani Gupta, "Development of High Intensity CDC Combustor for Gas Turbine Engines," Applied Energy, Vol. 88, 2011, pp. 963-973. doi:10.1016/j.apenergy.2010.07.038

[8] Antonio Cavaliere and Mara de Joannon, "Mild Combustion," Progress in Energy and Combustion Science, Vol. 30, 2004, pp. 329-366. doi:10.1016/j.pecs.2004.02.003

[9] G. Erwann, C. Michanel and G. Ephraim, "Application of "Flameless" Combustion for Gas Turbine Engines," 47th AIAA Aerospace Sciences Meeting Including The New Horizons Forum and Aerospace Exposition, Orlando, Florida, USA: AIAA 2009, Vol. 225, 5-8 January 2009, pp. 1-10.

[10] Y. Levy, G. Arvind Rao and S. Valery, "Chemical Kinetic and Thermodynamics of Flameless Combustion Methodology for Gas Turbine Combustors,"43rd AIAA/ASME/SAE/ASEE Joint Propulsion Conference\& Exhibit, 8-11 July 2007, Cincinnati, OH, AIAA 2007, Vol. 5629, pp. 1-18.

[11] J. C. Mi, P. F. Li and C. G. Zheng, "Impact of Injection Conditions on Flame Characteristics from a Parallel Multi-jet Burner Energy," Vol. 36, No. 11, 2011, pp. 6583-6595. doi:10.1016/j.energy.2011.09.003

[12] Fluent, "The FLUENT 6.3 User's Guide," Fluent Inc., 2005, http://www.fluent.com 
[13] R. Curtet, "Combust Flame,” Vol. 2, 1958, pp. 383-411.

[14] G. Erwann, C. Michael and G. Ephraim, "Application of 'Flameless' Combustion for Gas Turbine Engines," 47th
AIAA Aerospace Science Meeting Including The New Horizones Forum and Aerospace Exposition, Orlando, Florida, USA, 2009, pp. 1-10. 